\title{
LA ILEGALIDAD DEL RECHAZO EN FRONTERA Y DE LAS DEVOLUCIONES “EN CALIENTE” FRENTE AL TRIBUNAL DE DERECHOS HUMANOS Y AL TRIBUNAL CONSTITUCIONAL
}

\author{
THE ILLEGALITY OF BORDER REJECTION \\ AND "HOT" REFOULEMENT IN FRONT \\ OF THE EUROPEAN COURT OF HUMAN RIGHTS \\ AND THE SPANISH CONSTITUTIONAL COURT
}

\author{
Ana Fernández Pérez \\ Profesora titular de Derecho internacional privado \\ Universidad de Alcalá
}

Recibido: 15.06.2021 / Aceptado: 06.07.2021

DOI: https://doi.org/10.20318/cdt.2021.6255

\begin{abstract}
Resumen: La STEDH N.D. y N.T. c. España de 13 de febrero de 2020 y la STC 172/2020 de 19 de noviembre de 2020 permiten, sobre la base de ciertos condicionantes, una práctica ilegal en los ordenamientos jurídicos constitucionales, las devoluciones de extranjeros por "vía de hecho" prescindiendo de cualquier garantía jurídica. Partiendo de dichas sentencias se analizará la figura de la devolución regulada en la legislación española para posteriormente comprobar si las actuaciones realizadas en Ceuta y Melilla por las fuerzas y cuerpos de seguridad del estado se acomodan a la normativa de derechos humanos recogida en el Convenio europeo de Derechos humanos (CEDH) y sus protocolos así como en la Constitución española.

Palabras clave: devoluciones, rechazo en frontera, derechos humanos, procedimiento administrativo, extranjeros.

Abstract: The ECHR case N.D. and N.T. v. Spain of 13 February 2020 and Constitutional Court case 172/2020 of 19 November 2020 allow, on the basis of certain conditions, a practice that is illegal in constitutional legal systems, the return of foreigners by "de facto means" without any legal guarantee. Based on these rulings, the figure of refoulement regulated in Spanish legislation will be analysed in order to subsequently verify whether the actions carried out in Ceuta and Melilla by the state security forces and bodies comply with the human rights regulations set out in the European Convention on $\mathrm{Hu}-$ man Rights (ECHR) and its protocols, as well as in the Spanish Constitution.
\end{abstract}

Keywords: refoulement, refusal at the Border, human rights, administrative procedure, foreigners.

*Este trabajo se enmarca dentro del Module Jean Monnet «A More Social Europe: Citizenship, Asylum and Immigration» (MORE-UE) Ref. 611319-EPP-1-2019-1-ESEPPJMO-MODULE concedido por la Comisión europea a la autora. El artículo refleja únicamente las opiniones de la autora y la Comisión europea no se hace responsable del uso que pueda hacerse de la información contenido en él.estatal de I+D+i orientada a los retos de la sociedad. Ref.: RTI2018-099274-B-I00. IP: J.A. Fernández Avilés y M $\mathrm{M}^{\mathrm{a}} \mathrm{D}$. García Valverde. 
Sumario: I. Planteamiento. II. Introducción a la figura de la devolución. III. Las devoluciones sin las debidas garantías o devoluciones "en caliente" en Ceuta y Melilla. 1. Ausencia del correspondiente procedimiento administrativo. 2. Imposibilidad de identificación y recurso. 3. Incumplimiento del Acuerdo Hispano-marroquí. III. Las devoluciones “en caliente" en la doctrina del TEDH. 1. Planteamiento. 2. Justificación del rechazo a un extranjero por no haber presentado previamente una solicitud de protección internacional o visado. La conducta previa del interesado. 3. Justificación de las devoluciones en caliente en atención a la conducta de los extranjeros durante la entrada. 4. Imposibilidad de presentar recurso contra las devoluciones en caliente. IV. La Disposición Adicional $10^{\mathrm{a}}$ de la Ley de Extranjería: doctrina constitucional. 1. Regulación. 2. La errónea interpretación jurídica del rechazo en frontera por el TC. 3. (In)constitucionalidad de la Disposición Adicional $10^{\mathrm{a}}$ LOEX. V. Conclusiones.

\section{Planteamiento}

1. El legislador interno está fuertemente condicionado por la normativa internacional de derechos humanos, que debe impregnar todo el ordenamiento jurídico en el momento de establecer un determinado sistema de extranjería ${ }^{1}$. Las normas internas del Derecho de extranjería deben obligar al Estado a conceder un trato garante de derechos a los extranjeros que se hallan en su territorio respecto a su persona, sus bienes y sus actos y relaciones jurídicas ${ }^{2}$. Dentro de este sistema de extranjería los Estados, y condicionado por las normas de la Unión Europea ${ }^{3}$, pueden decidir acerca de la entrada, permanencia y salida de los nacionales de terceros estados en su territorio, así como a la prohibición de entrada de extranjeros a través de la denegación de entrada o la devolución.

2. Dentro del reconocimiento de los Estados de un trato mínimo a los extranjeros basado en la normativa de derechos humanos existe una limitación a los inmigrantes. Junto con el derecho de admisión que tienen los Estados existe también un derecho de devolución del territorio contra la voluntad de los mismos. Esta posibilidad se aplica a quienes se encuentren en el territorio de un Estado tanto legal como irregularmente. Sin embargo, este derecho no es absoluto y se encuentra restringido por un buen número de normas internacionales ${ }^{4}$. Ejemplos de tales restricciones son:

${ }^{1}$ G. Goodwin-Gill, "International Law and Human Rights: Trends Concerning International Migrants and Refugees", International Migration Review, vol. XXIII, $\mathrm{n}^{\circ}$ 3, 1989, pp. 526-546, esp. 526; M. Foucher, L'invention des frontières, París, Fondation pour les Études de Défense Nationale, 1986, pp. 56-58. El Derecho internacional general impone todo un conjunto de pautas, que se acentúan cada vez más en virtud de lo que W. RIPHAGEN calificase de "influencia de las relaciones interestatales sobre la solución de los problemas derivados de la coexistencia de sistemas jurídicos" ( $c f$. W. RiPHAGEN, "The Relationship between Public and Private Law and the Rules of Conflict of Laws", $R$. des C., t. 102, 1961-I, p. 293); frente al aparente desinterés de tiempos pasados (recuérdese el obiter dictum de la CPJI en el asunto de Lotus), puede afirmarse que hoy la situación ha variado sustancialmente y que este hecho es particularmente relevante en los círculos jurídicos con un cierto grado de integración.

2 J. DE LUCAs, “¿Cómo globalizar los derechos humanos? El test de la inmigración”, La globalización y los derechos humanos. IV Jornadas Internacionales de Derechos Humanos (Sevilla, 2003), Madrid, Talasa, 2004, pp. 361-393; M.J. AÑón (ed.), La universalidad de los derechos sociales: el reto de la inmigración, Valencia, Tirant lo blanch, 2004; J.A. CARRILlo SALCEDO, "El problema de la universalidad de los derechos humanos en un mundo único y diverso", Derechos culturales y derechos humanos de los inmigrantes, Madrid, Universidad Pontificia de Comillas, 2000, pp. 39-53; L. Ferrajoli, "De los derechos del ciudadano a los de la persona", Derechos y garantías. La ley del más débil, Madrid, Trotta, 1999, p. 37. Vid. de este autor, Los fundamentos de los derechos fundamentales, Madrid, Trotta, 2005; id., "Sobre los derechos fundamentales", Cuestiones Constitucionales, Revista Mexicana de Derecho Constitucional, no 15, 2006, pp. 116-117; P.A. DE Miguel Asensio, "Derechos humanos, diversidad cultural y Derecho internacional privado", Revista de Derecho Privado, 1998, pp. 541-558.

${ }^{3}$ Especialmente condicionado por el Reglamento (UE) 2016/399 por el que se establece el Código de fronteras Schengen y la Directiva 2008/115/CE relativa a normas y procedimientos comunes para el retorno de los nacionales de terceros países en situación irregular.

${ }^{4}$ Vid. J. C. Fernández Rozas, "Extranjería: Principios de Derecho internacional general”, Economía y Sociología del Trabajo, $\mathrm{n}^{\circ} 11,1991$, pp. 44-46. 
i) El principio de no devolución, incluido en el art. $33.1^{\circ}$ Convención de 1951 sobre el Estatuto de los Refugiados. Un principio similar se encuentra en el art. $3^{\circ}$ de la Convención contra la Tortura y Otros Tratos o Penas Crueles, Inhumanos o Degradantes de $1984^{5}$.

ii) El "interés superior del niño", reflejado en la Convención sobre los Derechos del Niño, puede anular el derecho de expulsión de un Estado a un no nacional. El derecho a vivir en familia puede limitar el derecho del Estado a devolver a un inmigrante del territorio.

3. Junto con estas restricciones particulares sobre el derecho de un Estado a devolver a un inmigrante, el Derecho internacional atribuye controles de procedimiento. En este sentido, un migrante regular o irregular tiene derecho inter alia a que su caso sea revisado antes de su devolución. Sin embargo, esta obligación de revisión por parte de los estados pueden ser obviadas cuando existan "razones convincentes de seguridad nacional". A pesar de ello, en numerosas ocasiones las devoluciones y las expulsiones se llevan a cabo obviando las limitaciones impuestas por el Derecho internacional al poder estatal ${ }^{6}$.

4. En el presente artículo se analizará la figura de la devolución regulada en la legislación española para posteriormente comprobar si las actuaciones realizadas en Ceuta y Melilla por las fuerzas y cuerpos de seguridad del estado se acomodan a la normativa de derechos humanos recogida en el Convenio europeo de Derechos humanos (CEDH) y sus protocolos. Para finalizar se estudiará la posible ilegalidad del "rechazo en frontera" introducido en la disposición adicional décima de la Ley de extranjería a través de la LO 14/2015 de Protección de la Seguridad Ciudadana tanto por su falta de encaje en el ordenamiento español como la nueva interpretación realizada indirectamente de las fronteras de Ceuta y Melilla?

\section{Introducción a la figura de la devolución}

5. El derecho a entrar en España no es un derecho fundamental del que sean titulares los extranjeros en atención al art. $19 \mathrm{CE}^{8}$. El 15 de marzo de 2006 el Parlamento Europeo y el Consejo aprobaron su Reglamento (UE) 2016/399 del Parlamento europeo y del Consejo de 9 de marzo de 2016 por el que se establece un Código de normas de la Unión para el cruce de personas por las fronteras (Código de fronteras Schengen), por el cual se completan, y también derogan preceptos del Convenio de Aplicación del Acuerdo de Schengen (CAAS). En este instrumento se incluyen las condiciones requeridas para permitir que un extranjero supere el perímetro exterior de la Unión Europea ${ }^{9}$. La entrada se encuentra condicionada al cumplimiento de los requisitos establecidos en el Código y en el art. 25 Ley Orgánica 4/2000 de extranjería (LOEx) y el art. 4 del RD 557/2011, de 20 de abril, por el que se aprueba su reglamento (RLOEx). Cuando la entrada se ha efectuado de manera irregular existen varios procedimientos

${ }^{5}$ L. BIANKU, "Le non-refoulement comme principe du droit international et le rôle de la Cour européenne des droits de l'homme dans sa mise en œuvre", Revue universelle des droits de l'homme, vol. 23, n 1, 2017, pp. 11-13, https://www.echr. coe.int/Documents/Dialogue_2017_FRA.pdf.

${ }^{6}$ P. MATHEw, "Constructive refoulement", Research handbook on international refugee law, Edward Elgar Publishing, Cheltenham", UK, 2019, pp. 207-223. La autora explora el concepto de “devolución constructiva", particularmente en relación con la práctica australiana y examina las posibles infracciones del art. 33 de la Convención de Refugiados cuando el estado hace lo posible para evitar que un solicitante de asilo o protección internacional se quede en su territorio.

${ }^{7}$ En este sentido se manifestó M. A. Acosta SÁNCHEz, "Las fronteras terrestres de España en Melilla: delimitación, vallas fronterizas y tierra de nadie", REEI, 2014, $\mathrm{n}^{\circ} 28, \mathrm{pp} .17$ y ss, expresa la problemática relativa a la dejación de soberanía al abandonar la denominada zona neutral en el momento de construcción de la valla de Melilla.

${ }^{8}$ STC 236/2007, de 7 de noviembre, FJ 12. Vid. E. SAGARra TRÍAs, La legislación sobre extranjería e inmigración: una lectura: los derechos fundamentales y las libertades públicas de los extranjeros en España, Universitat Autónoma de Barcelona, 2002, pp. 124.

${ }^{9}$ Las condiciones de entrada estaban definidas en el art. 5 del Convenio de Aplicación Schengen y en el Manual de Fronteras Exteriores, mediante un acto adoptado por el Comité Ejecutivo de Schengen, y con poco valor jurídico. Vid. I. LiRola DeLGADO, "El Código comunitario de normas para el cruce de personas por las fronteras. Comentario al Reglamento n. ${ }^{\circ}$ 562/2006 del Parlamento y del Consejo, de 15 de marzo de 2006”, Revista General de Derecho Europeo, n. ${ }^{\circ} 13$, mayo 2007, p. 2. 
relativos a la salida obligada del territorio español de las personas extranjeras, transpuestos algunos de ellos de la Directiva 2008/115/CE ${ }^{10}$ relativa a normas y procedimientos comunes para el retorno de los nacionales de terceros países en situación irregular, que son relevantes a estos efectos:

i) la denegación de entrada y el retorno al punto de origen (art. $60 \mathrm{LOEx}$ ), como efecto derivado de la prohibición de entrada en España por los puestos fronterizos habilitados de extranjeros que no cumplan los requisitos legalmente previstos (art. 26.2 ${ }^{\circ}$ LOEx y art. 15 RLOEx);

ii) la salida obligatoria o la expulsión del extranjero que se encuentra irregularmente en territorio español, por no haber obtenido la prórroga de estancia o por carecer o tener caducada la autorización de residencia (art. 57 LOEx y arts. 242-248 RLOEx);

iii) la devolución de los que habiendo sido expulsados contravengan la prohibición de entrada

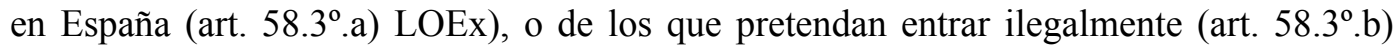
LOEx), incluyendo "a los extranjeros que sean interceptados en la frontera o en sus inmediaciones” (art. 23.1 $1^{\circ}$.b) RLOEx).

6. En el ordenamiento español la devolución es una medida de restablecimiento inmediato del orden jurídico perturbado cuando un extranjero accede de manera irregular al territorio de un Estado, que se acuerda por resolución administrativa de la autoridad gubernativa competente para la expulsión, previa la instrucción del correspondiente expediente administrativo. No se trata de un procedimiento sancionador y tiene todas las garantías establecidas en la normativa interna y en la normativa de Derechos humanos. El proceso de devolución que recoge el artículo 58 LOEx y que se desarrolla en el art. 23 RLOEx de aplicación a los supuestos de entrada irregular o de incumplimiento de una prohibición de entrada por estar vigente una orden de expulsión recoge una serie de garantías jurídicas acordes con la normativa de derechos humanos ${ }^{11}$ que implica, por ejemplo, el derecho a ser identificado, la asistencia jurídica y de intérprete, la posibilidad de solicitar protección internacional o la asistencia sanitaria en caso de que sea necesario. Por desgracia, desde hace ya más de una década en los territorios de Ceuta y Melilla se realizan un tipo de devoluciones sin las debidas garantías, devoluciones por vía de hecho o "en caliente" que incumplen la normativa aludida.

\section{Las devoluciones sin las debidas garantías o devoluciones "en caliente" en Ceuta y Melilla}

\section{Ausencia del correspondiente procedimiento administrativo}

7. Se produce una devolución "en caliente" cuando el Estado devuelve a un extranjero sin respetar los derechos y garantías que tanto la normativa internacional como la $\mathrm{UE}^{12}$ y la propia $\mathrm{LOEx}^{13}$ reconoce a todo individuo, práctica habitual en las ciudades autónomas de Ceuta y Melilla. Estos derechos son Derechos Humanos esenciales provenientes de la Declaración Universal de los Derechos humanos (DUDH), Convención europea de Derechos humanos (CEDH) y la Carta de Derechos fundamentales

\footnotetext{
${ }^{10}$ En este sentido, vid. F. LüTz, "Non-removable Returnees under Union Law: Status Quo and Possible Developments", European journal of migration and law, vol. 20, n. 1, 2018, p. 28-52 acerca del Derecho de la Unión europea aplicable a la devolución de extranjeros y posibles vías de solución en el caso de no poder ser devueltos; I. MaJCHER, "The European Union Returns Directive and its compatibility with international human rights law: analysis of return decision, entry ban, detention, and removal", The European Union Returns Directive and its compatibility with international human rights law : analysis of return decision, entry ban, detention, and removal, Leiden / Boston, Brill / Nijhoff, 2019.

${ }^{11}$ Un estudio sobre del cumplimiento de las políticas europeas y el cumplimiento de los Derechos humanos puede verse en S. Cogolati, "Les politiques migratoires extérieures de l'Union européenne a l'épreuve des droits de l'homme", Journal de droit européen, vol. 24, n 229, 2016, pp. 175-181.

${ }^{12}$ Art. 19 CDFUE.

${ }^{13}$ Un estudio en detalle sobre las devoluciones puede verse en A. FernÁndez Pérez, "La regulación de las devoluciones y expulsiones de extranjeros la ilegalidad de las devoluciones de extranjeros efectuadas sin las debidas garantías", Diario La Ley, $\mathrm{n}^{\mathrm{o}} 8382,2014$.
} 
de la Unión Europea (CDFUE) $)^{14}$ y deben ser reconocidos a toda persona, sin que quepa ningún tipo de distinción o discriminación en su reconocimiento o ejercicio.

8. Como expusimos más arriba, la LOEx reconoce expresamente a todo extranjero objeto de expulsión o devolución una serie de derechos y garantías como el derecho a la asistencia letrada ${ }^{15} \mathrm{y}$ el derecho a un intérprete, si no comprende el idioma, el derecho a solicitar protección internacional, etc. La garantía para acceder a los procedimientos administrativos es la identificación individualizada de las situaciones que rodean a las personas, y especialmente que puedan acceder a ellos personas particularmente vulnerables como los menores de edad, los demandantes de asilo o de protección internacional ${ }^{16}$, víctimas de trata, o personas enfermas. Ante una devolución "en caliente" todos estos derechos son vulnerados de manera flagrante. Pero fundamentalmente se vulnera el derecho a solicitar la protección internacional recogida el art. $58.4^{\circ}$ LOEx que establece que el extranjero que se encuentre en situación de ser devuelto, tiene derecho a presentar dicha solicitud y no podrá efectuarse la devolución "hasta que se haya decidido la inadmisión a trámite de la petición, de conformidad con la normativa de protección internacional" 17 . Las devoluciones "en caliente" imposibilitan, asimismo, que víctimas de trata de seres humanos, de mafias o de redes criminales organizadas ("tráfico ilícito de seres humanos, inmigración ilegal, explotación laboral o de tráfico ilícito de mano de obra o de explotación en la prostitución abusando de su situación de necesidad"), puedan prestar su colaboración con las autoridades españolas ${ }^{18}$.

9. Los menores de edad o las personas afectadas por serios motivos de incapacidad, y mujeres embarazadas son las que más sufren por las devoluciones en caliente ${ }^{19}$. En especial resulta muy difícil identificar a un menor de edad sin ningún procedimiento médico, como constata el dictamen del Comité de Derechos del Niño de 12 de febrero de 2019 (CRC/C/80/D/4/2016), por el que condena a España por una expulsión sumaria de un menor no acompañado que trataba de acceder por la valla de Melilla ${ }^{20}$.

${ }^{14}$ Art. $8 \mathrm{CEDH}$, art. $13 \mathrm{CEDH}$ y art. $47 \mathrm{CDFUE}$.

${ }^{15} \mathrm{El}$ art. 22 LOEx regula el derecho a la asistencia jurídica gratuita de los extranjeros en España en los siguientes términos:

"1. Los extranjeros que se hallen en España y que carezcan de recursos económicos suficientes según los criterios establecidos en la normativa de asistencia jurídica gratuita tienen derecho a ésta en los procedimientos administrativos o judiciales que puedan llevar a la denegación de su entrada, a su devolución o expulsión del territorio español y en todos los procedimientos en materia de asilo. Además, tendrán derecho a la asistencia de intérprete si no comprenden o hablan la lengua oficial que se utilice.

2. Los extranjeros residentes que acrediten insuficiencia de recursos para litigar tendrán derecho a la asistencia jurídica gratuita en iguales condiciones que los españoles en los procesos en los que sean parte, cualquiera que sea la jurisdicción en la que se sigan".

${ }^{16}$ X. POTTIER, "La question du 'refoulement indirect' et de la 'clause discrétionnaire' au sein du système 'Dublin III'”, Revue du droit public et de la science politique en France et à l'étranger, $\mathrm{n}^{\circ}$ 5, 2020, pp. 1385-1420.

${ }^{17}$ Este derecho aparece regulado en el art. 7 del Pacto Internacional de Derechos Civiles y Políticos (PIDCP), el art. 5 de la Carta de Banjul y el art. 5.2 de la Convención Americana de Derechos Humanos, art. 4 del Protocolo n 4 CEDH y art 19 CDFUE.

${ }^{18}$ En este sentido, la STJUE de 25 de junio de 2020, asunto C-36/20, determina que el art. $6.1^{\circ}$ de la Directiva 2013/32/UE del Parlamento Europeo y del Consejo, de 26 de junio de 2013, sobre procedimientos comunes para la concesión o la retirada de la protección internacional, establece la posibilidad de que la solicitud de protección internacional se formule no solo ante la autoridad competente para su registro sino también ante otras autoridades que, pese a ser probable que reciban tales solicitudes, no sean competentes para registrarlas, citando expresamente a la policía, guardias de fronteras, autoridades de inmigración y personal de los centros de internamiento, imponiendo la obligación a los Estados de que estas autoridades dispongan de la información pertinente y su personal reciba la formación necesaria acorde a sus funciones y responsabilidades, así como instrucciones, para informar a los solicitantes sobre dónde y cómo pueden presentarse las solicitudes de protección internacional.

${ }^{19} \mathrm{C}$. Cournil, “Aux 'confins des droits' des mineurs étrangers non accompagnés détenus et refoulés : à propos de la décision de la CEDH du 12 octobre 2006, Mubilanzila Mayeka et Kaniki Mitunga c/ Belgique, nr. 13178/03”, Revue critique de droit international privé, vol. 97, n'. 1, 2008, pp. 35-59; R. CADIN, "La riconsegna sommaria dei migranti, inclusi i minori stranieri non accompagnati, dall'Italia alla Grecia: la condanna della Corte europea dei diritti dell'uomo nel caso Sharifi”, I minori stranieri in Italia : Atti del Convegno in memoria di Maria Rita Saulle e Lê Quyên NgôĐinh, Ariccia (RM), Aracne, 2014, pp. 241-251.

${ }^{20}$ Resulta destacable el caso D.D. c. España, resuelto por el Comité de los Derechos del Niño de Naciones Unidas, Dictamen $\mathrm{CRC} / \mathrm{C} / 80 / \mathrm{D} / 4 / 2016$, en donde el Estado español ha sido condenado por un rechazo en frontera involucrando a un menor. En este caso, el Comité dictaminó que se había producido una violación de la prohibición de tortura consagrada en el art. 37 de la Convención de los Derechos del Niño (Instrumento de Ratificación de la Convención sobre los Derechos del Niño, adoptada por la Asamblea General de las Naciones Unidas el 20 de diciembre de 1989 (BOE n 313, de 31 de diciembre de 1990)), habida cuenta, entre otros factores, de la violencia que sufren los migrantes en la zona fronteriza y de la ausencia de análisis por parte de las au- 
El dictamen determinó que este tipo de devoluciones de hecho, practicadas por los funcionarios públicos españoles, supone el incumplimiento de las obligaciones internacionales contempladas en el 20.1 (protección debida por el Estado a toda persona menor privada de su medio familiar) y 37 (no sometimiento a las personas menores a torturas ni a otros tratos o penas crueles, inhumanos o degradantes) de la Convención de Derechos del Niño, en la medida en que no permite someter a un menor a un proceso de identificación y evaluación de su situación personal y de la existencia de un riesgo de persecución y/o daño irreparable previa a su entrega a las autoridades de Marruecos y no se le da la oportunidad de presentar objeciones a esa devolución ${ }^{21}$.

\section{Imposibilidad de identificación y recurso}

10. Como expusimos, la normativa española sobre devolución de extranjeros obliga a las autoridades a identificar a los individuos para poder iniciar un procedimiento administrativo individualizado antes de ser devueltos a su país de origen Así lo determinó también la STEDH por la que se resuelve el caso Hirsi Jamaa y otros c. Italia que obliga a los Estados a que se proceda a la identificación y al análisis individualizado de la situación de cada persona que pretende entrar irregularmente. Al instarse las devoluciones inmediatas no es posible identificar individualmente en cada caso a cada extranjero, y en ausencia de cualquier identificación, información o procedimiento se les priva de recurso interno con respecto a su devolución, incluidos los recursos previstos por la legislación nacional y de la $\mathrm{UE}^{22}$. El Tribunal recuerda la plena aplicabilidad del CEDH a todas las actuaciones de control migratorio y de fronteras efectuadas por las autoridades de un Estado parte de la Convención ${ }^{23}$.

11. De la jurisprudencia del TEDH ${ }^{24}$ se desprende que el art. 4 del Protocolo $\mathrm{n}^{\mathrm{o}} 4$ tiene como objetivo mantener la posibilidad, para cada uno de los extranjeros interesados, de denunciar un riesgo de tratamiento incompatible con el Convenio, y en particular con el art. 3, en caso de que la devolución exponga a cualquier persona a un riesgo. Por esa razón, el art. 4 del Protocolo $\mathrm{n}^{\mathrm{o}} 4$ requiere que las autoridades estatales se aseguren de que cada uno de los extranjeros tenga la posibilidad efectiva de presentar argumentos contra su devolución. Esto no quiere decir que cuando varios extranjeros estén sujetos a similares decisiones cada uno de los procedimientos conlleve la existencia de una expulsión colectiva en atención al art. 4 del Protocolo $n^{\circ} 4$ del Convenio si cada persona interesada ha tenido la oportunidad de interponer argumentos en contra de su devolución a las autoridades competentes de forma individual, lo contrario si lo supondría ${ }^{25}$. Los requisitos de esta disposición solo pueden cumplirse

toridades españolas del riesgo que suponía devolver al menor a Marruecos (Comité de los Derechos del Niño, 2019, p. 12). http:// www.fundacionraices.org/wp-content/uploads/2016/03/CRC-C-80-DR-4-2016_devolucion-sumaria-menor-de-edad-Melilla.pdf

${ }^{21}$ Dictamen CRC/C/80/D/4/2016, aps. 14.7 y 14.8 .

${ }^{22} \mathrm{~S}$. KRISPER, The European Union's safe country concepts versus the principle of non-"refoulement", Tesis doctoral, Universität Wien, 2012: el autor defiende que los factores de gravedad en virtud del art. 3 del CEDH por sí solos son, en primer lugar, la falta de disponibilidad de un recurso efectivo y el efecto suspensivo de los procedimientos contra una decisión de expulsión en el tercer Estado receptor y, en segundo lugar, la falta de cierta calidad del procedimiento único del tercer Estado, teniendo como resultado en el caso respectivo un alcance de protección más restrictivo que el previsto por la definición de refugiado universal.

${ }^{23}$ Un análisis de esta sentencia se puede ver en C. DE CAStro SÁnchez, "Tribunal Europeo de Derechos Humanos - TEDH - Sentencia de 23.02.2012 (Gran Sala), Hirsi Jamaa y otros. c. Italia, 27765/09. `Artículo 3 y 13 del CEDH; Artículo 4 del Protocolo $\mathrm{n}^{\circ} 4$ - Tortura y tratos inhumanos y degradantes - derecho a un recurso efectivo - prohibición de las expulsiones colectivas de extranjeros'", Revista de Derecho Comunitario Europeo, no 17.46, 2013, pp. 1119-1135 y M.D. Bollo Arocena, "Push back, expulsiones colectivas y non refoulement. Algunas reflexiones a propósito de la sentencia dictada por la gran sala del TEDH en el caso Hirsi Jamaa y otros c. Italia (2012)", VVAA, El Derecho internacional en el mundo multipolar del siglo XXI: obra homenaje al profesor Luis Ignacio Sánchez Rodríguez, Iprolex, Madrid, 2013, pp. 647-666.

${ }^{24}$ Vid. STEDH (Sección tercera), Čonka c. Bélgica, demanda $\mathrm{n}^{0}$ 51564/99, de 5 de febrero de 2002; STEDH (Sección tercera), Sultani c. Francia, demanda n n $^{\circ} 5223 / 05$, de 20 de septiembre de 2007 y STEDH (Gran Sala), Hirsi Jamaa y otros c. Italia, demanda $\mathrm{n}^{\circ} 27765 / 09$, de 23 de febrero de 2012, entre otras.

${ }^{25}$ Para A. Chueca SAncho el que varias decisiones de expulsión presenten una redacción idéntica debería ser un identificador clave para que el TEDH considere la expulsión como colectiva. Vid. A. ChUECA SANCHO, "El Derecho internacional prohíbe las expulsiones colectivas de extranjeros", Revista de Derecho Migratorio y Extranjería, no 1, 2002, 9-36, p. 23. 
cuando cada extranjero tiene una posibilidad efectiva de presentar argumentos contra su expulsión o devolución, y donde esos argumentos sean examinados de una manera apropiada por las autoridades del Estado demandado ${ }^{26}$.

12. La falta de identificación en las devoluciones en caliente efectuadas en Ceuta y Melilla impide la presentación de recursos ante las autoridades españolas, lo que vulnera claramente el art. $13 \mathrm{CEDH}$ :

"Toda persona cuyos derechos y libertades según lo establecido en [la] Convención sean violados tendrá un recurso efectivo ante una autoridad nacional a pesar de que esa violación ha sido cometida por personas que actúan a título oficial".

Como vemos el art. 13 de la Convención garantiza la disponibilidad a nivel nacional de un recurso para hacer cumplir los derechos y libertades de la Convención en cualquier forma para que puedan estar aseguradas. El efecto de esa disposición requiere, por lo tanto, la provisión de un recurso interno para tratar el fondo de una "queja" bajo la Convención y para conceder la solución apropiada.

\section{Incumplimiento del Acuerdo Hispano-marroquí}

13. El Acuerdo entre el Reino de España y el Reino de marruecos relativo a la circulación de personas, el tránsito y la readmisión de extranjeros entrados ilegalmente, firmado en Madrid el 13 de febrero de 1992 cuya entrada en vigor se produjo el 21 de octubre de 2012, no es un instrumento jurídico en el que las autoridades españolas puedan amparar las denominadas devoluciones en caliente en detrimento de la aplicación de los procedimientos establecidos en la LOEx. Tampoco a partir de su articulado se pueden justificar actuaciones de entrega a las autoridades marroquís por vía de hecho sin la realización del correspondiente procedimiento administrativo previo. El Acuerdo expresamente establece la necesidad de realización de un procedimiento en el que se harán constar todos los datos disponibles relativos a la identidad, a la documentación personal eventualmente poseída por el extranjero y a las condiciones de su entrada ilegal en el territorio del Estado requirente, así como cualquier otra información de que se disponga sobre el mismo ${ }^{27}$. De la literalidad del art. 2 se desprende la necesidad de que en España se haya realizado un procedimiento administrativo con todas las garantías para poder proceder a la devolución del extranjero ${ }^{28}$.

Por otro lado, es necesario entender que el Acuerdo hispano-marroquí es un acuerdo de readmisión. Eso no significa que por el hecho de existir dicho acuerdo no sea necesario que previamente a esa readmisión se haya instruido el correspondiente procedimiento administrativo con todas las garantías exigibles en la LOEx y la ley de procedimiento administrativo. Por tanto, el Acuerdo hispano-marroquí y la LOEx son normas compatibles y no excluyentes que, en ningún caso, regulan una misma actividad administrativa. En este sentido, la LOEx regula los procedimientos en virtud de los cuales un ciudadano

${ }^{26}$ Vid. STEDH (Gran Sala), Khlaifia y otros c. Italia de 15 de diciembre de 2016, párr. 248: los representantes los solicitantes no pudieron indicar "el más mínimo fundamento fáctico o legal que, según el Derecho internacional o nacional, podrían haber justificado presencia en territorio italiano y excluir [d] su expulsión". Esto llamó a cuestionar la utilidad de una entrevista individual en ese caso (ibid., párr. 253).

${ }^{27}$ I. GonZÁlez García, "El acuerdo España-Marruecos de readmisión de inmigrantes y su problemática aplicación: las avalanchas de Ceuta y Melilla", Anuario Español de Derecho internacional (Universidad de Navarra), vol XXII, 2006, pp. 255-284.

${ }^{28}$ Art. 2 Acuerdo Hispano-Marroquí: "La readmisión se efectuará si se aprueba, por cualquier medio, que el extranjeros cuya readmisión se solicita proviene efectivamente del territorio del Estado requerido.

La solicitud de readmisión deberá ser presentada en los diez días posteriores a la entrada ilegal en el territorio del Estado requerido. En ella se harán constar todos los datos disponibles relativos a la identidad, a la documentación personal eventualmente poseída por el extranjero y a las condiciones de su entrada ilegal en el territorio del Estado requirente, así como cualquier otra información de que se disponga sobre el mismo.

Cuando la readmisión es aceptada, se documenta mediante la expedición por las Autoridades de frontera del Estado requerido de un certificado o de cualquier otro documento en el que se hace constar otro documento en el que se hace constar la identidad y, en su caso, la documentación poseída por el extranjero en cuestión”. 
extranjero puede ser devuelto a otro territorio. Por el contrario, el Acuerdo hispano-marroquí regula la forma de ejecución de la readmisión del inmigrante en territorio marroquí, es decir, una vez que las autoridades administrativas españolas han resuelto expulsar o devolver a un inmigrante, y es ahí, cuando comienza a aplicarse el acuerdo de readmisión ${ }^{29}$.

14. El Acuerdo regula una serie de obligaciones. Por un lado, los arts. 1 y 2 exigen una petición formal de las autoridades fronterizas del Estado requirente, en la que deberán constar "todos los datos disponibles relativos a la identidad, documentación personal eventualmente poseída por el extranjero y las condiciones de su entrada ilegal en territorio del Estado requirente, así como cualquier otra información que se disponga sobre el mismo". Igualmente se establece que "cuando la readmisión es aceptada, se documenta mediante la expedición por las Autoridades de frontera del Estado requerido de un certificado o de cualquier otro documento en el que se hace constar la identidad y, en su caso, la documentación poseída por el extranjero en cuestión". En ese sentido, al margen de las obligaciones derivadas de la legislación de extranjería, el Acuerdo regula una serie de obligaciones recíprocas para la ejecución de las entregas que excluyen, sin lugar a dudas, cualquier tipo de actuaciones administrativas por vías de hecho. Se hace, entonces, necesario diferenciar que el procedimiento regulado en el art. 58 LOEx para la devolución, establece las garantías previas para poder realizar dicha devolución ${ }^{30}$, mientras que el Acuerdo hispano marroquí regula la forma en que debe realizarse dicha readmisión cuando el lugar de destino del extranjero está en Marruecos.

Por tanto, el Acuerdo hispano-marroquí de readmisión no justifica la aplicación de las llamadas devoluciones "en caliente" por no ser susceptible, en función de la materia que regula, de excepcionar la aplicación de los procedimientos establecidos en la legislación de extranjería. Al contrario, este Acuerdo establece nuevas obligaciones para la ejecución en materia de estas entregas de ciudadanos extranjeros ${ }^{31}$.

\section{Las devoluciones "en caliente" en la doctrina del TEDH}

\section{Planteamiento}

15. Existe un amplio consenso dentro de Europa con respecto a la obligación y la necesidad de que los Estados miembros protejan sus fronteras: ya sea sus propias fronteras o las fronteras externas del área Schengen, según sea el caso, cumpliendo con las garantías establecidas en la CEDH, y en particular con la obligación del principio de no devolución a los solicitantes de asilo ${ }^{32}$ o protección internacional ${ }^{33}$.

\footnotetext{
${ }^{29}$ M. Martínez Escamilla, “'Devoluciones en caliente'. Guerra sucia en la Frontera Sur”, Crítica, Ejemplar dedicado a: Las migraciones en un mundo globalizado, ${ }^{\circ}$ 994, 2014, pp. 41-46.

${ }^{30} \mathrm{El}$ art. 23 RLOEx deja claro que "el extranjero respecto del cual se sigan trámites para adoptar una resolución de devolución" no sólo tendrá que ser llevado "a la mayor brevedad posible" a Comisaría, sino que también "tendrá derecho a la asistencia jurídica, así como a la asistencia de intérprete" con las garantías traspuestas del art. 12 de la Directiva 2008/115/ $\mathrm{CE}$ del Parlamento Europeo y del Consejo referidas al derecho efectivo a interponer recurso contra las decisiones relativas al retorno o pidiendo que se revisen.

${ }^{31}$ Informe jurídico "Expulsiones en caliente: cuando el Estado actúa al margen de la ley" http://eprints.ucm.es/25993/1/ INFORME\%20\%20EXPULSIONES\%20EN\%20CALIENTE.\%20 27_6_2014\%20\%281\%29.pdf

${ }^{32}$ El Reglamento de Dublín determina el Estado miembro responsable del examen de una solicitud de protección internacional presentada en uno de los Estados miembros de la Unión Europea y constituye la piedra angular del Sistema Europeo Común de Asilo. Su objetivo es combatir los movimientos secundarios de solicitantes de asilo al establecer una única oportunidad para presentar una solicitud de protección internacional en Europa. Para ello, se basa en la idea de que los solicitantes de asilo serían tratados por igual y tendrían la misma oportunidad de recibir protección internacional en todos los Estados miembros de la UE. Si bien esto ha sido cuestionado en la práctica desde la llamada crisis de refugiados en 2015, esta premisa se cuestiona más fundamentalmente por el principio de «no devolución» en virtud del Derecho internacional de los derechos humanos, que establece los límites del sistema de Dublín y revela sus defectos sistémicos, vid. C. BAUlOz, "Le règlement Dublin à l'épreuve du principe de non-refoulement : chronique d'une crise annoncée", Revue suisse de droit international et de droit européen, vol. 27, nº 2, 2017, pp. 139-150.

${ }^{33} \mathrm{Vid}$. J.C. Simeon, "What is the future of non-refoulement in international refugee law?, Research handbook on international refugee law, Edward Elgar Publishing, Cheltenham, UK, 2019, pp. 183-206; O. LE FORT, La preuve et le principe de non-refoulement : entre droit international des réfugiés, protection des droits humains et droit suisse des migrations, Ginebra,
} 
En los Estados firmantes del CEDH, como España, cuyas fronteras coinciden, al menos en parte, con las fronteras exteriores del espacio Schengen, la efectividad de los derechos de la Convención requiere que estos Estados pongan a disposición de los extranjeros acceso legítimo y efectivo a los medios de entrada legal, en particular, los procedimientos para quienes han llegado a la frontera. Esos medios deberían permitir a todas las personas que se enfrentan a una persecución poder presentar una solicitud de protección basada en particular en el art. 3 de la Convención, bajo unas condiciones que aseguren que la solicitud se procese de manera coherente con las normas internacionales, incluida la Convención ${ }^{34}$. El Código de fronteras Schengen, en su art. 4.1 establece que las fronteras externas solo se pueden cruzar en los puntos de cruce y durante el horario de apertura, presuponiéndose la existencia de un número suficiente de puntos de cruce. En ausencia de dichos pasos fronterizos existe la posibilidad de que los Estados rechacen la entrada a su territorio y puedan hacer ineficaces todas las disposiciones de la Convención diseñadas para proteger a las personas que se enfrentan a un riesgo de persecución.

Las primeras demandas planteadas ante el TEDH por las devoluciones por la "vía de hecho" o "en caliente" tardaron en llegar debido a la complejidad de presentar una demanda en estas instancias "tanto por las dificultades reales que plantea la prueba e identificación de las víctimas de estas prácticas como por los diferentes intentos seguidos para intentar obtener un pronunciamiento de las instancias judiciales españolas" sin posibilidad de recurso previo ${ }^{35}$.

16. En la primera sentencia referida a las devoluciones en caliente en Ceuta y Melilla del TEDH N.D. y N.T. c. España de 3 de octubre de 2017, el Tribunal declaró inadmisible la queja planteada por los demandantes en relación con la vulneración del art. 3 del Convenio que regula la prohibición de la tortura, y admitió las quejas relativas al art. 4 del Protocolo $\mathrm{n}^{\circ} 4$, que se refiere a la prohibición de las expulsiones colectivas de extranjeros y al art. 13 del Convenio, respecto al derecho a un recurso efectivo y de estos dos artículos puestos en relación. Esto supuso una vulneración flagrante del art. $13 \mathrm{CEDH}$ por el estado español en relación con el art. 4 del Protocolo $\mathrm{n}^{\circ} 4 \mathrm{CEDH}$ admitiendo que los extranjeros, en las devoluciones en caliente, son privados de cualquier recurso impidiéndoles presentar su queja de conformidad con el art. 4 del Protocolo $\mathrm{n}^{\circ} 4 \mathrm{CEDH}$ ante una autoridad competente y para obtener una minuciosa y rigurosa evaluación de sus solicitudes antes de ser devueltos ${ }^{36}$. Existe una prohibición internacional con respecto a las expulsiones colectivas recogida en numerosa doctrina del $\mathrm{TEDH}^{37}$. Las medidas ejecutadas

Schulthess / Éditions romandes, 2018; L. BIANKU, "Le non-refoulement comme principe du droit international et le rôle de la Cour européenne des droits de l'homme dans sa mise en œuvre", Revue universelle des droits de l'homme, vol. 23, $\mathrm{n}^{\circ}$ 1-12, 2017, pp. 11-13, https://www.echr.coe.int/Documents/Dialogue_2017_FRA.pdf; H. RaspaIL, "Le principe de non-refoulement en situation d'afflux massif", Revue trimestrielle des droits de l'homme, vol. 29, n 115, julio 2018, pp. 613-650.

${ }^{34}$ F. DE WECK, Non-refoulement under the European Convention on Human Rights and the UN Convention Against Torture : the assessment of individual complaints by the European Court of Human Rights under Article 3 ECHR and the United Nations Committee Against Torture under Article 3 CAT, Leiden / Boston,: Brill Nijhoff, 2017, donde se puede ver una comparación de la jurisprudencia y la práctica del Tribunal Europeo de Derechos Humanos y el Comité de las Naciones Unidas contra la Tortura en casos individuales relacionados con el principio de no devolución, en casos de expulsión y extradición presentados por personas en virtud del art. 3 del Convenio Europeo de Derechos Humanos (CEDH) o del art. 3 de la Convención de las Naciones Unidas contra la Tortura y Otros Tratos o Penas Crueles, Inhumanos o Degradantes. Vid. también C. Costello, y M. Foster, "Non-refoulement as Custom and Jus Cogens? Putting the Prohibition to the Test", Netherlands Yearbook of International Law, vol. 46, 2015, pp. 273-327.

${ }^{35}$ J.M. SÁnchez Tomás, "Las 'devoluciones en caliente' en el Tribunal Europeo de Derechos Humanos (STEDH, AS. N.D. y N.T. vs España, de 03.10.2017)”, Revista Española de Derecho Europeo, nº 65 (enero-marzo 2018), 2018; C. Soler GARCíA, "La prohibición de las expulsiones colectivas de extranjeros en la jurisprudencia del Tribunal europeo de Derechos Humanos: especial referencia al caso de España”, Revista General de Derecho Europeo, no 45, 2018, pp. 107-160.

${ }^{36}$ STEDH (Sección Tercera), N.D. y N.T. c. España, de 3 de octubre de 2017, el Tribunal consideró que esta queja era "discutible" para el propósito del artículo 13 CEDH. Vid. STEDH Hirsi Jamaa y otros, párr. 201.

${ }^{37}$ C. Soler García, "La prohibición de las expulsiones colectivas ...", loc. cit.; M. D. Bollo Arocena, "Límites personales y materiales al derecho de los Estados a la expulsión de extranjeros. Una visión desde el Derecho internacional Público", Cursos de Derecho internacional y Relaciones Internacionales de Vitoria Gasteiz 2012, Madrid, Tecnos, 2012, pp. 111-186; C. DE CAStro SÁnchez, "El CEDH como límite de las políticas migratorias europeas", Revista de Derecho Comunitario Europeo, núm. 46, 2013, pp. 1119 - 1135; A. Solanes Corella, "Contra la normalización de la ilegalidad: La protección judicial de los extranjeros frente a las expulsiones colectivas las "devoluciones en caliente", Cuadernos Electrónicos de Filosofía del Derecho, no 36,2017 , pp. 196-225. 
a través de las devoluciones en "caliente" sin decisión judicial o administrativa previa, sin procedimiento administrativo y sin identificación de las personas, permitió al TEDH en su sentencia de 2017 considerar que estas actuaciones eran expulsiones colectivas prohibidas por el art. 4, Protocolo $\mathrm{n}^{\mathrm{o}} 4$ (prohibición de expulsión colectiva de extranjeros) $\mathrm{CEDH}$ y del art. $13 \mathrm{CEDH}$ (derecho a un recurso efectivo).

17. Posteriormente, la Gran Sala en su Sentencia de 13 de febrero de 2020 a pesar de admitir esta vulneración por parte del estado español consideró la falta de culpabilidad del mismo en atención al criterio para la interpretación de tales artículos, la "conducta previa del interesado". En consecuencia, de acuerdo con la jurisprudencia del TEDH, los Estados pueden rechazar la entrada a su territorio a extranjeros, incluidos posibles solicitantes de asilo y menores, que no han solicitado el acceso legal al territorio, cuando pretendan cruzar la frontera por un lugar no habilitado, especialmente, en la valla de Ceuta y Melilla, aprovechando su gran número y el "uso de la fuerza". Las expulsiones colectivas, aunque vulneren el art. 4 del Protocolo $n^{\circ} 4 \mathrm{CEDH}$, pueden ser aceptadas, según el TEDH, cuando exista una conducta culpable atribuible al interesado por no haber presentado previamente una solicitud de protección internacional o un visado de entrada siempre que se realicen en gran número y con uso de la fuerza ${ }^{38}$.

\section{Justificación del rechazo a un extranjero por no haber presentado previamente una solicitud de protección internacional o visado. La conducta previa del interesado}

18. Uno de los argumentos esgrimidos por la Gran Sala en su Sentencia de 13 de febrero de 2020 (N.D. y N.T. c. España) para declarar que no había vulnerado el art. 4 del Protocolo n 4 CEDH fueron los "esfuerzos realizados por España", en respuesta a los flujos migratorios en sus fronteras, para aumentar el número de puestos fronterizos oficiales, puntos de cruce y mejorar el derecho de acceso efectivo a ellos, y por lo tanto, para hacer más seguro, en beneficio de aquellos que necesitan protección, la posibilidad de acceder a los procedimientos establecidos a tal efecto.

19. El Tribunal admitió que, en virtud del art. 38 de la Ley 12/2009 los cónsules y embajadores españoles podían garantizar el traslado a España de personas en necesidad de protección a través de varios medios para solicitar la admisión al territorio nacional ${ }^{39}$, ya sea solicitando un visado o la protección internacional, en particular en la frontera de Beni-Enzar, pero también en las representaciones diplomáticas y consulares de España en los países de origen de los extranjeros o tránsito o en Marrue$\cos ^{40}$. La disponibilidad y accesibilidad real de estas vías legales se discutió en detalle en los procedimientos de la Gran Sala que dio lugar a la Sentencia de 13 de febrero de 2020. El Tribunal consideró que las autoridades españolas habían establecido una oficina para el registro de solicitudes de asilo ("la Unidad Especial de Protección Internacional"), abierta las 24 horas, en el paso fronterizo internacional de Beni-Enzar, incluso antes de la creación de una oficina de registro de asilo, se había establecido una vía legal a tal efecto en virtud del art. 21 de Ley 12/2009. El Gobierno español alegó que la devolución de los demandantes había sido consecuencia de su propia "conducta culpable" a los fines de la reiterada jurisprudencia del TEDH. Los solicitantes habían intentado ingresar al territorio español de forma no autorizada ${ }^{41}$ y de ninguna manera los solicitantes habían podido demostrar que no pudieron utilizar los "numerosos" procedimientos legales disponibles para obtener permiso para cruzar la frontera hacia

\footnotetext{
${ }^{38}$ Un estudio más en profundidad acerca de las sentencias del TEDH se puede ver en A. FERnÁndEZ Pérez, "El control de las fronteras exteriores de la Unión Europea: las devoluciones en caliente", Ciudadanía, asilo e inmigración en la Unión Europea, I Foro europeo de Derecho internacional privado, coord. A. Fernández Pérez, Iprolex, Madrid, 2020, pp. 111-150.

${ }^{39}$ Para un estudio en profundidad del art. 38 de la Ley de asilo vid. A. SÁnChEz Legido, "Entre la obsesión por la seguridad y la lucha contra la inmigración irregular. A propósito de la nueva ley de asilo", REEI, vol. 18, 2009, pp. 21 y ss.

${ }^{40}$ Vid. arts. 21 y 38 de la Ley 12/2009, y los Artículos 4, 16 y 29 (4) del Real Decreto 203/1995. El estudio de J.V. GonzÁLEZ GarCía, "Expulsiones 'en caliente', devoluciones y petición de asilo en Ceuta y Melilla", Revista de Administración Pública, n 196,2015 , pp. 309-329 analiza claramente las dificultades que tienen los solicitantes de asilo o protección internacional de presentar sus solicitudes en Ceuta y Melilla.

${ }^{41}$ Vid. Art. 25 LOEx.
} 
España. El gobierno argumentó que estaba "abierto a cualquier extranjero que deseara ingresar a España para solicitar asilo o protección internacional" a través del Paso fronterizo de Beni Enzar ${ }^{42}$ o en la embajada española en Rabat o en los consulados españoles en Marruecos (en particular en Nador), o una Embajada española o Consulado en otro país ${ }^{43}$. Por lo tanto, los solicitantes "podrían, si hubieran necesitado solicitar asilo u obtener protección internacional por otros motivos presentar tal reclamo a las instituciones antes mencionadas" ${ }^{44}$.

20. Los demandantes, por su parte, impugnaron la afirmación del Gobierno de que el Estado demandado les había brindado opciones legales y efectivas para la entrada legal en España. Enfatizaron la imposibilidad de obtener acceso a la mayoría de los lugares mencionados por el Gobierno, especialmente para individuos del África subsahariana. La justificación de por qué las personas subsaharianas no presentaron sus solicitudes de protección en los puestos fronterizos se debió, según el ACNUR y el Comisionado para los Derechos Humanos del Consejo de Europa, a que físicamente, en la práctica, es imposible o muy difícil para personas de África subsahariana en Marruecos acceder a estos puestos ${ }^{45}$.

21. A este argumento, entendió el TEDH, que los perfiles raciales o controles de pasaportes severos en el lado marroquí, no sugieren que el Gobierno español fuera de ninguna manera responsable de estas cuestiones. Los demandantes, según el TEDH (Gran Sala), no cuestionaron la posibilidad efectiva de solicitar un visado en las embajadas españolas, ya sea en sus países de origen o en uno de los países donde los Solicitantes habían viajado desde 2012. Para el Tribunal, en el caso de ND, un tratado especial entre España y Mali ofrecía una posibilidad adicional de obtener una visa de trabajo especial ${ }^{46}$.

${ }^{42}$ Vid. art. 21 Ley 12/2009. Una visión distinta de la argumentada por el Gobierno español se puede ver en "Sin protección en la frontera. Derechos humanos en la frontera sur: entre Nador y Melilla" del Servicio Jesuita a Migrantes e Instituto Universitario de Estudios Sobre Migraciones, octubre de 2017, https://sjme.org/wp-content/uploads/2017/10/sin-proteccionen-la-frontera.pdf en el que se afirma que "A principios de 2015 se habilitaron dos Oficinas de Asilo y Refugio del Ministerio del Interior en el paso fronterizo de Beni-Enzar. Como hemos descrito en el apartado anterior, no es fácil acceder a las mismas, debido al control previo de la policía marroquí: prácticamente todas las personas sirias acaban comprando documentación falsa para cruzar la frontera; y las personas subsaharianas ni siquiera pueden acceder al puesto fronterizo".

${ }^{43}$ Por el contrario, en el informe "Sin protección en la frontera. Derechos humanos en la frontera sur: entre Nador y Melilla" del Servicio Jesuita a Migrantes e Instituto Universitario de Estudios Sobre Migraciones, octubre de 2017, https://sjme.org/wpcontent/uploads/2017/10/sin-proteccion-en-la-frontera.pdf, se afirma que "Tampoco les facilitó la posibilidad de solicitar asilo o un visado humanitario en el Consulado de España en Nador, tal como prevé el artículo 38 de la Ley de Asilo. Algunas ONG, como CEAR, instaron esta posibilidad. Los propios refugiados sirios se manifestaron delante del Consulado en dos ocasiones, en septiembre de 2015 ".

${ }^{44}$ Vid. art. 38 de Ley 12/2009. Una visión contraria a la alegada por el Gobierno español se puede ver en CEAR, "El Consulado de Nador, una oportunidad para solicitar refugio de forma segura", 28 de julio de 2015, https://www.cear.es/el-consuladode-nador-una-oportunidad-para-solicitar-refugio-de-forma-segura/. La CEAR afirmó que "Las Embajadas y Consulados de España en Marruecos, especialmente el situado en Nador, deben permitir la posibilidad de solicitar protección internacional, tal y como contempla la Ley de Asilo. Así lo ha reclamado hoy la Comisión Española de Ayuda al Refugiado (CEAR).

En sendas cartas enviadas a los titulares de los ministerios del Interior y de Asuntos Exteriores y Cooperación, la organización señala que con esta se medida evitaría que muchas personas tengan que arriesgar su vida en el mar o saltando las vallas de Ceuta y Melilla para presentar su solicitud de asilo".

${ }^{45}$ CEAR, "Informe 2018: Las personas refugiadas en España y Europa" https://www.asylumineurope.org/sites/default/ files/resources/informe-anual-cear-2018.pdf afirma que "Cabe resaltar que a la población de procedencia subsahariana le sigue resultando imposible cruzar la frontera hispano-marroquí porque las autoridades del país vecino lo impiden. Por tanto, no pueden acceder a las oficinas de asilo habilitadas en la frontera y solo pueden solicitar la protección internacional aquellas que han logrado cruzarla de forma irregular, escondidas en el interior de vehículos o saltando la valla fronteriza".

${ }^{46}$ STEDH N.D y N.T. c. España de 2020. "No parece que el demandante, especialmente si era solicitante de asilo o protección internacional, pudiera cumplir con los requisitos establecidos en el art. 3 del Acuerdo Marco de Cooperación en materia de inmigración entre el Reino de España y la República de Mali, hecho en Madrid el 23 de enero de 2007: "1. Las Partes contratantes impulsarán la contratación legal de nacionales de la otra Parte contratante en su territorio, previo el análisis de sus mercados de trabajo y de la complementariedad de éstos, cuando las cualificaciones profesionales de los nacionales de la Parte contratante de origen casen con las necesidades de las empresas y empleadores de la Parte contratante de acogida. 2. La Parte contratante de acogida favorecerá los contactos entre dichas empresas y empleadores y el interlocutor designado por la Parte contratante de origen, y canalizará a dicho órgano designado como interlocutor las ofertas de empleo formuladas por las citadas empresas y empleadores. Las Partes contratantes intercambiarán información sobre la situación de sus mercados de trabajo, a través de los interlocutores que para ello se designen. 3. La contratación legal de los nacionales de la Parte contratante de origen en la Parte 
22. El TEDH destaca que la Convención tiene por objeto garantizar los derechos de aquellos que se encuentran dentro de su jurisdicción, pero únicamente derechos prácticos y efectivos no derechos teóricos e ilusorios ${ }^{47}$. Considera que el deber general para un Estado contratante bajo el art. 4 del Protocolo $\mathrm{n}^{\mathrm{o}} 4$ no es traer personas que están bajo la jurisdicción de otro Estado dentro de su propia jurisdicción aunque existan dificultades para acercarse físicamente a este paso fronterizo en el lado marroquí. Por lo que no puede achacarse ninguna responsabilidad del Gobierno español por esta situación. Esta conclusión fue suficiente para que la Gran Sala concluyera que no ha habido ninguna violación del art. 4 del Protocolo No. 4 en el asunto en atención a la conducta de los interesados al no solicitar asilo en los puestos fronterizos o en las embajadas o consulados españoles.

23. A la luz de estas observaciones, el Tribunal consideró que los solicitantes no hicieron uso de procedimientos legales existentes para obtener la entrada legal al territorio español de conformidad con las disposiciones del Código de fronteras Schengen relativas al cruce de las fronteras exteriores del espacio Schengen. En consecuencia, de conformidad con su jurisprudencia reiterada, el Tribunal ${ }^{48}$ consideró que la falta de decisiones de expulsión individuales puede atribuirse al hecho de que los solicitantes, no hicieron uso de los procedimientos oficiales de entrada existentes para ese propósito, y por lo tanto, la falta de identificación y su devolución inmediata fue consecuencia de su propia conducta ${ }^{49}$.

\section{Justificación de las devoluciones en caliente en atención a la conducta de los extranjeros durante la entrada}

24. Para determinar si un Estado incumple la normativa de Derechos humanos de acuerdo con el art. 4 del Protocolo $n^{\circ} 4$ CEDH respecto a la prohibición de las expulsiones colectivas es necesario determinar la conducta previa y durante la entrada del solicitante de acuerdo con la doctrina del TEDH. Analizada en el apartado anterior la conducta previa la jurisprudencia establecida por el Tribunal determina que no existe vulneración del artículo 4 de Protocolo $\mathrm{n}^{\circ} 4$ si la falta de una decisión de expulsión o devolución individual es debida a la propia conducta del solicitante ${ }^{50}$. La Gran Sala consideró que los demandantes, en el presente caso, eran miembros de un grupo compuesto por numerosas personas que intentaron entrar en territorio español cruzando una frontera terrestre en un lugar no autorizado, aprovechando su gran número y en el contexto de una operación que había sido planificada de antemano. Que

contratante de acogida será conforme con los procedimientos laborales vigentes en ésta y se regirá por su legislación sobre la materia. 4. Los nacionales de Mali que no se hallen o residan en España podrán ser contratados en el marco del contingente anual de trabajadores extranjeros que en su caso apruebe el Gobierno español siempre que reúnan los requisitos establecidos para ello. 5. Cada Parte contratante proseguirá sus esfuerzos tendentes a facilitar, en el marco de la legislación vigente, la expedición de visados de estancia múltiple a nacionales de la otra Parte contratante en los casos en que el solicitante del visado sea personal directivo u hombres de negocios, investigadores o científicos, profesores universitarios, artistas o intelectuales de reconocido prestigio, deportistas profesionales de alto nivel, que participen activamente en las relaciones económicas, sociales, científicas, universitarias, culturales y deportivas entre ambos países".

${ }^{47}$ Vid. entre otras STEDH Airey c. Irlanda, 9 de octubre de 1979, párr. 24; STEDH (Gran Sala) Leyla Şahin c. Turquía, demanda $\mathrm{n}^{\circ}$ 44774/98, de 10 de noviembre de 2005, párr. 136; STEDH Hirsi Jamaa y otros, citado anteriormente, párr. 175; y STEDH Ibrahim y otros c. Reino Unido (Gran Sala), demanda nº 50541/08 y 3 más, de 13 de septiembre de 2016, párr. 272.

${ }^{48}$ Vid. mutatis mutandis, STEDH (Gran Sala) Khlaifia y otros c. Italia de 15 de diciembre de 2016, párr. 253; sin embargo, vid. también las opiniones de Comité de los Derechos del Niño de 12 de febrero de 2019 en virtud del Protocolo Facultativo de la Convención sobre los Derechos del Niño sobre un procedimiento de comunicación, relativo a la comunicación $\mathrm{n}^{\circ}$ 4/2016. http:// www.fundacionraices.org/wp-content/uploads/2016/03/CRC-C-80-DR-4-2016_devolucion-sumaria-menor-de-edad-Melilla.pdf

49 Á. SÁnchez Legido, "Las devoluciones en caliente españolas ante el tribunal de Estrasburgo", Revista española de Derecho internacional, vol. 72, $\mathrm{n}^{\circ} 2$ (julio-diciembre 2020), pp. 235-259, considera que este concepto es "un ciego aval a las políticas de externalización de controles migratorios, el Tribunal afirma expresamente la irrelevancia de la ausencia de vías de acceso cuando la inaccesibilidad no responde a motivos de los que sean responsables los Estados europeos".

${ }^{50}$ Vid. Khlaifia y otros, cit. párr. 240, y Hirsi Jamaa y otros, cit. párr. 184; vid. también STEDH (Sección cuarta) MA c. Chipre, demanda n $n^{\circ}$ 41872/10, de 23 de julio de 2013, párr. 247; STEDH, Berisha y Haljiti c. "La ex República Yugoslava de Macedonia", demanda ${ }^{\circ}$ 18670/03, de 16 de junio de 2005; y STEDH, Dritsas y otros c. Italia, demanda n ${ }^{\circ} 2344 / 02$, de 1 de febrero de 2011; vid. C. Soler García, "La prohibición de las expulsiones colectivas de extranjeros en la jurisprudencia del Tribunal europeo de Derechos Humanos: especial referencia al caso de España”, Revista General de Derecho Europeo, n 45, 2018, pp. 107-160. 
los solicitantes se pusieron en peligro al participar en el asalto de las vallas fronterizas de Melilla el 13 de agosto de 2014, aprovechando el numeroso grupo y el uso de la fuerza. Tuvo en cuenta, además, que las reclamaciones de los solicitantes en virtud del art. 3 fueron declaradas inadmisibles por el Tribunal de instancia en su Sentencia de $2017^{51}$.

25. El TEDH discurrió que este mismo principio también debía aplicarse a las situaciones en la cual la conducta de las personas que cruzan una frontera terrestre por un lugar no autorizado aprovechando deliberadamente su gran número y el uso de la fuerza, para crear una situación claramente disruptiva que es difícil de controlar y pone en peligro la seguridad pública. No obstante, esta conclusión debe ser entendida, según la Gran Sala, junto con las circunstancias del caso particular, el Estado demandado proporcionó acceso efectivo a los medios legales entrada, y en particular en los procedimientos fronterizos. Cuando el Estado demandado proporciona dicho acceso pero el solicitante no hace uso de él, el Tribunal considera, y sin perjuicio de la aplicación de arts. 2 y 3 del CEDH, que aunque hubiera razones convincentes para no hacerlo, el Estado demandado no es responsable ${ }^{52}$.

\section{Imposibilidad de presentar recurso contra las devoluciones en caliente}

26. El TEDH confirmó que no se puede plantear un derecho al recurso al no tener acceso los extranjeros, antes de su devolución, a ningún procedimiento de identificación y comprobación de sus circunstancias personales. El carácter inmediato de la devolución de facto priva a los demandantes de toda vía de recurso que les permita presentar ante una autoridad su queja en relación con el art. 4 del Protocolo $n^{\circ} 4^{53}$.

27. Al contrario que la argumentación esgrimida por el TEDH (Sala $3^{\mathrm{a}}$ ) en 2017, para la Gran Sala la falta de un recurso con respecto a los demandantes no constituye en sí misma una violación del art. 13 del Convenio debido a que al ponerse los demandantes en peligro participando en el salto de las vallas fronterizas impidieron ellos mismos que las autoridades españolas les pudieran identificar. Al no poder justificar por qué no habían intentado acceder a España por las vías legales, es decir, solicitando un visado en su país de origen, en los países de tránsito o pidiendo asilo en los consulados o en la embajada de España en Marruecos el Tribunal considera que la devolución en caliente fue consecuencia de la propia conducta de los solicitantes, y, que, por lo tanto, no existe violación del artículo 13 del Convenio.

\section{La Disposición Adicional 10ª de la Ley de Extranjería: doctrina constitucional}

\section{Regulación}

28. En este marco legal se inserta la controvertida disposición adicional décima de la $\operatorname{LOEx}^{54}$, introducida por la LOPSC, posteriormente a los acontecimientos que dieron lugar a las STEDH de 2017

${ }^{51}$ STEDH (Sección Tercera), N.D. y N.T. c. España, de 3 de octubre de 2017 y STEDH (Gran Sala), N.D. y N.T. c. España, de 13 de febrero de 2020.

${ }^{52}$ Esta jurisprudencia choca con la anterior doctrina del TEDH Saadi c. Italia (Gran Sala), demanda n ${ }^{\circ} 37201 / 06$, de 28 de febrero de 2008, párrs. 124-125, donde "la conducta anterior del demandante, por indeseable o peligrosa que haya sido, no es un elemento a tener en cuenta para la expulsión".

${ }^{53}$ STEDH (Sección Tercera), N.D. y N.T. c. España, de 3 de octubre de 2017.

${ }^{54}$ La Ley Orgánica 4/2015, de 30 de marzo, de protección de la seguridad ciudadana (LOPSC) introdujo una disposición adicional décima a la Ley Orgánica 4/2000, de 11 de enero, sobre derechos y libertades de los extranjeros en España y su integración social, estableciendo un régimen especial para las devoluciones en Ceuta y Melilla con el siguiente tenor

"1. Los extranjeros que sean detectados en la línea fronteriza de la demarcación territorial de Ceuta o Melilla mientras intentan superar los elementos de contención fronterizos para cruzar irregularmente la frontera podrán ser rechazados a fin de impedir su entrada ilegal en España.

2. En todo caso, el rechazo se realizará respetando la normativa internacional de derechos humanos y de protección internacional de la que España es parte.

3. Las solicitudes de protección internacional se formalizarán en los lugares habilitados al efecto en los pasos fronterizos y se tramitarán conforme a lo establecido en la normativa en materia de protección internacional”. 
y 2020 (NT y ND c. España). que prevé en su apartado 1 el "rechazo en frontera" de los extranjeros que sean detectados en la línea fronteriza de la demarcación territorial de Ceuta o Melilla. Los otros dos apartados de la disposición adicional tienen un carácter instrumental: se precisa cómo ha de hacerse el rechazo (apdo. 2) y dónde se han de formalizar, en su caso, las solicitudes de protección internacional (apdo. 3).

La reforma operada por la Disposición Final primera de la LO 4/2015 que adiciona una Disposición adicional décima a la LOEx parece desconocer totalmente la legislación de extranjería, el Derecho internacional público y la normativa de derechos humanos ya que, como hemos visto, para poder llevar a cabo una devolución de un extranjero se debe seguir un procedimiento administrativo que cumpla las garantías establecidas en la ley. El propio Comisario de Derechos Humanos del Consejo de Europa había recomendado de manera reiterada desde 2005 que las prácticas de las devoluciones en caliente cesaran ${ }^{55}$.

\section{La errónea interpretación jurídica del rechazo en frontera por el TC}

29. La Disposición adicional $10^{\mathrm{a}}$ de la LOEx introducida a través de la LOPSC impide la tramitación de un procedimiento administrativo para las devoluciones realizadas en la valla que cumpla las garantías establecidas en la ley y en la normativa de Derechos humanos. Ante una devolución "en caliente", todos estos Derechos son vulnerados de manera flagrante. Pero fundamentalmente se vulnera el derecho a solicitar la protección internacional recogida en el art. 58.4 $4^{\circ}$ LOEx que establece que el extranjero que se encuentre en situación de ser devuelto tiene derecho a presentar dicha solicitud y no podrá efectuarse la devolución "hasta que se haya decidido la inadmisión a trámite de la petición, de conformidad con la normativa de protección internacional" y la Convención de Derechos del niño ${ }^{56}$.

30. El problema de esta disposición adicional es querer incluir un régimen especial de devoluciones sin garantías jurídicas a Ceuta y Melilla que además modifica la frontera española con Marrue$\cos ^{57}$. Esta disposición rompe con la regulación establecida en la propia LOEx e introduce una distinción específica para las devoluciones de Ceuta y Melilla, a las que deja sin garantías jurídicas en la práctica con respecto a las reguladas en el art. 58 LOEx. La experiencia demuestra que no se permite la identificación de menores ${ }^{58}$ o el ejercicio de la petición del derecho de asilo; configura un procedimiento especial para los grupos de personas que pretenden entrar en nuestro territorio desde dos únicos enclaves, a los que reducen las garantías con respecto al régimen general contraviniendo la obligación que tiene el Estado de realizar un trato individualizado de cada caso en concordancia con la prohibición de expulsiones colectivas, las cuales están expresamente prohibidas en los casos de devolución, expulsión y extradición por el art. $19.1^{\circ}$ CDFUE.

\footnotetext{
${ }^{55}$ Informe de Á. Gil-Robles, Comisario de Derechos Humanos en su visita a España 10-19 de marzo de 2005, https:// rm.coe.int/16806db842, p. 41 y ss.

${ }^{56}$ Como ya expuso el dictamen del Comité de Derechos del Niño de 12 de febrero de 2019 (CRC/C/80/D/4/2016).

${ }^{57}$ Las fronteras, las aguas interiores y el mar territorial se fijan por normas internacionales de obligado cumplimiento por España. En las ciudades de Ceuta y Melilla existe un doble vallado: una valla interna y una valla externa. La valla externa ha sido levantada por el Gobierno español y está construida sobre territorio español. Por tanto, el Estado ejerce plenamente allí su soberanía. Las playas de las ciudades autónomas de Ceuta y Melilla, sus aguas interiores, y el mar territorial conforman parte del territorio español. En este sentido, J.A. del Valle Gálvez y M.A. Acosta Sánchez consideran que "el problema de la Disposición Adicional de la Ley Orgánica es que al decir que el vallado ("elementos de contención fronterizos") es la demarcación territorial de las Ceuta y Melilla, está aceptando el control y la jurisdicción que ejerce Marruecos sobre el territorio español más allá de la valla exterior. Este territorio sería aproximadamente unos 180.000 metros cuadrados en el caso de Ceuta y unos 144.600 metros cuadrados en el caso de Melilla", en "Delimitación y demarcación de las fronteras y vallas de Ceuta y Melilla ¿Cesión territorial a Marruecos?”, La Unión Europea y los muros materiales e inmateriales: Desafios para la seguridad, la sostenibilidad y el estado de derecho / A. Salinas de Frías y E. J. Martínez Pérez (dirs.), 2021, pp. 21-50, esp. 48.

58 "El Estado parte debe revisar la disposición adicional décima de dicha ley en relación con el "Régimen Especial de Ceuta y Melilla," la cual autorizaría la práctica indiscriminada del Estado parte de deportaciones automáticas en su frontera" de acuerdo con el Dictamen aprobado por el Comité en relación con el Protocolo Facultativo de la Convención sobre los Derechos del Niño relativo a un procedimiento de comunicaciones respecto de la Comunicación $\mathrm{n}^{\circ} 4 / 2016$. http://www.fundacionraices.org/ wp-content/uploads/2016/03/CRC-C-80-DR-4-2016_devolucion-sumaria-menor-de-edad-Melilla.pdf.
} 
31. El "rechazo en frontera" de la disposición adicional décima de la LOEx no tiene ninguna justificación jurídica. Si se interpreta conforme a la STC no hay ninguna distinción entre la DA $10^{\mathrm{a}}$ y la devolución prevista en el art. 58.3 LOEx, en los términos que se expusieron en la STC 17/2013, de 31 de enero, FJ 12, para diferenciarla de la expulsión y que son trasladables al presente caso. Con la devolución -y también con el rechazo en frontera-, se "pretende evitar la contravención del ordenamiento jurídico de extranjería, por lo que no comporta en sí misma una sanción sino una medida gubernativa de reacción inmediata frente a una perturbación del orden jurídico, articulada a través de un cauce flexible y rápido [...] En suma [...] consiste en una medida que se acuerda por parte del Estado español en el marco de su política de extranjería, en la que se incluye tanto el necesario control de los flujos migratorios que tiene como destino nuestro país como el establecimiento de los requisitos y condiciones exigibles a los extranjeros para su entrada y residencia en España"59.

32. Para el TC en su STC 172/2020, de 19 de noviembre de 2020, parece razonable y justo el establecimiento de un régimen específico para Ceuta y Melilla por su singularidad ubicación geográfica, al ser la única frontera exterior del espacio Schengen en tierras africanas. Para ello se apoya en la STEDH (NTy ND c. España) de la Gran Sala de 2020 que afirmó que España había tomado medidas para la protección internacional o solicitudes de visado en los países de origen, tránsito y Marruecos ${ }^{60}$ y que los solicitantes habían accedido por puestos no habilitados valiéndose de un gran número y del uso de la fuerza ${ }^{61}$.

33. Como ya expusimos, la alusión realizada por el TEDH a la situación específica en que se produce el cruce irregular de la línea fronteriza intentado por las personas extranjeras prevaliéndose de su gran número y del uso de la fuerza es la condición necesaria para justificar la devolución en caliente conforme al art. 4 de Protocolo 4 CEDH. Pero el TC va más allá y considera que, para la aplicación de la DA $10^{\mathrm{a}}$, no es necesario que se aprecien las circunstancias de actuación en grupo numeroso y con violencia, sino que basta el intento por personas individualizadas de entrar en España y ser sorprendidos en las vallas fronterizas de Ceuta y Melilla. Esta interpretación choca, como vemos, con la doctrina del TEDH que es el intérprete máximo de las garantías del CEDH y sus protocolos ${ }^{62}$, al ampliar el TC la aplicabilidad de este precepto a supuestos no autorizados como la "aplicación a las entradas individualizadas" lo que contradice, por tanto, que la DA $10^{\text {a }}$ LOEx se aplique con el "cumplimiento de las obligaciones internacionales".

34. El "rechazo en frontera" en Ceuta y Melilla es un nuevo régimen para una situación muy particular: la detección de extranjeros en la línea fronteriza de la demarcación territorial de Ceuta o Melilla mientras intentan superar los elementos de contención fronterizos una vez cruzada irregularmente la frontera; que permite que la Administración y sus agentes practiquen una actuación material de vigilancia orientada a reestablecer inmediatamente la legalidad transgredida por el intento de cruce

${ }^{59}$ STC 17/2013, de 31 de enero, FJ 12.

${ }^{60}$ STEDH (Gran Sala) de 13 de febrero de 2020, caso N.D. y N.T. c. España, párr. 211: "en este contexto, sin embargo, el Tribunal, al valorar una queja relativa al art. 4 de Protocolo 4, tendrá principalmente en cuenta si, en las circunstancias del caso concreto, el Estado Parte en cuestión ofrece de un modo efectivo medios de entrar en él legalmente, en particular a través de procedimientos en frontera. Cuando el Estado parte facilita este acceso y el recurrente no ha hecho uso de él, el Tribunal considerará $[\ldots]$ si había razones imperiosas para no usar esos medios de acceso, fundadas en hechos objetivos de los que el Estado correspondiente sea responsable".

${ }^{61}$ STEDH (Gran Sala) de 13 de febrero de 2020, caso N.D. y N.T. c. España, párr. 210: "cuando tales mecanismos [de entrada legal] existan y aseguren el derecho de pedir la protección que otorga la Convención, y en particular su art. 3, de un modo efectivo, la Convención no obsta a que los Estado Parte, en cumplimiento de su obligación [Schengen] de controlar las fronteras, exijan que las personas que quieran esa protección la soliciten en los puntos habilitados para el cruce de frontera. [...] Consecuentemente, los Estados Parte pueden rechazar la entrada en su territorio de los extranjeros, incluido los peticionarios de asilo, que, sin concurrir razones imperiosas, no hayan ajustado su conducta a estos mecanismos de entrada sino que han buscado cruzar la frontera por lugares distintos a los habilitados, sobre todo pero no necesariamente cuando, como ocurre en este caso, se prevalieron de su gran número y del uso de la fuerza".

${ }^{62}$ STEDH Assanidze c. Georgia, demanda n ${ }^{\circ} 71503 / 01$, de 4 de agosto de 2004, párr. 167; Hirsi Jamaa y otros c. Italia, cit., párr. 184; Ghulami c. Francia, demanda n ${ }^{\circ}$ 45302/05, de 7 de abril de 2009; (decisión de admisibilidad); Sultani c. Francia, cit., párr. 81. Čonka c. Bélgica, cit., párr. 59. 
irregular de frontera sin las debidas garantías. El TC la considera "una actuación material de carácter coactivo, que tiene por finalidad restablecer inmediatamente la legalidad transgredida por parte de las personas extranjeras que intentaron cruzar irregularmente esa concreta frontera terrestre". El "rechazo en frontera" se realiza cuando se intercepta a la persona que está intentando superar el vallado, pero, en ningún caso, comprende el acto administrativo posterior, es decir, su entrega a los agentes de la autoridad de Marruecos. De acuerdo con el voto particular emitido por la Magistrada María Luisa Balaguer Callejón en la STC 172/2020, de 19 de noviembre, la entrega a Marruecos es una devolución jurídica en sentido estricto. El "rechazo en frontera" o denegación de entrada está recogido en el art. 25 LOEx y presupone que la entrada que se pretende efectuar no es clandestina sino, al contrario, conocida de la autoridad española, que, en su caso, la deniega por no cumplirse todos los requisitos procedentes para su autorización y conlleva el retorno del extranjero ${ }^{63}$. El extranjero aún no ha entrado en el territorio y se produce en los puestos fronterizos habilitados al efecto ${ }^{64}$.

35. Por el contrario, la DA $10^{\mathrm{a}}$ se refiere al caso de que el extranjero interceptado ya se encuentre en territorio español ${ }^{65}$, y bajo custodia de funcionarios españoles ${ }^{66}$. En este caso, no se puede hablar de rechazo en frontera porque la persona interceptada está ya en territorio nacional ${ }^{67}$. Lo que se pretende es impedir que se mantenga en territorio nacional mediante su repatriación al lugar de procedencia por lo que se trata de una devolución que ya se encontraba regulada en el art. 58 LOEx.

Para justificar esta regulación el Gobierno español alteró los límites fronterizos con Marruecos para interpretarlos en atención al concepto "operativo" de frontera, a efectos de no aplicarse el régimen general recogido para las devoluciones de extranjeros en el art. 58 LOEx. La aplicación práctica de este concepto supone la limitación de derechos y libertades reconocidos en la LOEx y el CEDH en una parte del territorio español, mediante una modificación unilateral de la frontera, y a los solos efectos de la LOEx, lo que claramente resulta incompatible con el carácter territorial de la jurisdicción, en el sentido del art. 1 del $\mathrm{CEDH}^{68}$. No cabe duda de que los límites fronterizos del Estado español están recogidos por los Acuerdos con Marruecos que delimitan las ciudades autónomas de Ceuta y Melilla ${ }^{69}$. Las vallas fueron instaladas dentro del territorio español, en ejercicio de su soberanía. Por tanto, en la zona vallada y sus inmediaciones el Estado español debe someter sus actuaciones al respeto de los derechos y libertades recogidos por el CEDH. Especialmente teniendo en cuenta que las actuaciones de control fronterizo que se ejecutan en esta zona son llevadas a cabo por autoridades españolas en el ejercicio de sus funciones y sujetas, por lo tanto, a lo establecido en la ley interna. El hecho de que un extranjero se encuentre en territorio español, ya sea en una valla o nadando en aguas jurisdiccionales españolas, es suficiente motivo para que dicha persona obtenga una serie de garantías que la legislación establece para los ciudadanos que se encuentren en nuestro país. El Acuerdo entre España y Marruecos para la readmisión de extranjeros irregulares tampoco presenta ninguna duda sobre el objeto de la misma. No supone ningún amparo a las devoluciones en caliente o rechazos en frontera. Cualquier actuación que se realice

${ }^{63}$ Vid. con carácter general, J.L. RodríGuez CANDELA, "Medidas de alejamiento del territorio nacional: denegación de entrada-retorno, devolución y expulsión por estancia irregular", Inmigración, Estado y Derecho: perspectivas desde el siglo XXI (M. Balado Ruiz-Gallegos, coord.), Barcelona, Bosch, 2008, pp. 487-506.

${ }^{64}$ Las diferentes figuras para la salida o rechazo de extranjeros en A. FernÁndez Pérez, "La regulación de las devoluciones y expulsiones de extranjeros la ilegalidad de las devoluciones de extranjeros efectuadas sin las debidas garantías”, Diario La Ley, $\mathrm{n}^{\circ} 8382,2014$

${ }^{65}$ J.A. del Valle Gálvez y M.A. Acosta Sánchez "Delimitación y demarcación de las fronteras y vallas de Ceuta y Melilla ..", op. cit., esp. 41

${ }^{66}$ Los agentes españoles, como empleados públicos españoles que son, quedan sometidos al imperio de la ley española y al CEDH. En este sentido, vid. la STC 21/1997, de 10 de febrero, FJ 2.

${ }^{67}$ Vid. J.A. Del Valle Gálvez y M.A. Acosta SÁnChez "Delimitación y demarcación de las fronteras y vallas de Ceuta y Melilla ...", loc. cit., esp. 41; Informe jurídico "Expulsiones en caliente: cuando el Estado actúa al margen de la ley" http:// eprints.ucm.es/25993/1/INFORME\%20\%20EXPULSIONES\%20EN\%20CALIENTE.\%2027_6_2014\%20\%281\%29.pdf, p. 8.

${ }^{68}$ S. KIM, "Non-Refoulement and Extraterritorial Jurisdiction : State Sovereignty and Migration Controls at Sea in the European Context", Leiden Journal of International law, vol. 30, nº 1, 2017, pp. 49-70 entiende que el concepto de soberanía estatal ha comenzado a experimentar un cambio de paradigma de los derechos humanos de ámbito extraterritorial relacionadas con los controles de migración externa directamente dentro de un marco legal.

${ }^{69}$ Vid. J.A. Del Valle Gálvez y M.A. Acosta SÁnChez, "Delimitación y demarcación ...?", loc. cit. 
en la valla debe considerarse como un acto administrativo y, por tanto, debe tener las debidas garantías del procedimiento administrativo.

\section{3. (In)constitucionalidad de la Disposición Adicional $10^{\mathrm{a}}$ LOEX}

36. Concretada la naturaleza del régimen de "rechazo en frontera", es necesario determinar si la DA $10^{\text {a }}$ de la Ley de extranjería puede ser considerada constitucional. En el recurso de inconstitucionalidad llevado a cabo ante el TC que dio lugar a la STC 172/2020 los recurrentes alegaron que el precepto conculcaba el marco constitucional derivado de los arts. $9.3^{\circ}$ y $106.1^{\circ} \mathrm{CE}$, en conexión con el art. 24.1 ${ }^{\circ}$ CE. Alegaron que estábamos ante un supuesto de "vía de hecho", al tratarse de una actuación administrativa llevada a cabo prescindiendo de todo procedimiento. De hecho, la disposición claramente indica el rechazo del extranjero para posteriormente permitir tramitar las solicitudes de protección internacional en los lugares habilitados al efecto en los pasos fronterizos (fuera del territorio español) conforme a lo establecido en la normativa en materia de protección internacional y la normativa internacional de derechos humanos de la que España es parte. Pero en ningún caso habla de procedimiento alguno dentro del territorio nacional.

37. A pesar de la defectuosa redacción del precepto el TC consideró que existe un derecho a la completa tramitación de un procedimiento administrativo con una resolución sobre el fondo del asunto en materia de extranjería otorgado por el art. $106 \mathrm{CE}$ siempre que los interesados tengan derecho a recurrir a los Tribunales los actos que consideren incumplidos por parte de la Administración ${ }^{70}$. Este derecho a recurrir choca con una actuación material de carácter coactivo en las ciudades autónomas de Ceuta y Melilla que tiene por finalidad la de restablecer inmediatamente la legalidad transgredida por el intento por parte de las personas extranjeras de cruzar irregularmente esa concreta frontera terrestre. Actuación material que, según el TC, lo será, sin perjuicio del control judicial que proceda realizarse en virtud de las acciones y recursos que interponga, en cada caso concreto, la persona extranjera. El problema es que si no existe una identificación previa del extranjero y una posterior resolución administrativa de "rechazo" no se puede recurrir ante la autoridad administrativa o judicial y no existirá control del acto administrativo. La entrega física de una persona bajo jurisdicción española a otra jurisdicción, con todas las "implicaciones que ello supone en cuanto a la titularidad de derechos, incluyendo los derechos fundamentales, de la persona afectada es de tal relevancia y magnitud jurídica que, desde la perspectiva constitucional, no cabe admitir que se considere una mera actuación material que no precise de algún tipo de procedimiento en que se dé cumplimiento a unas mínimas garantías" ${ }^{\prime 71}$.

38. El régimen de "rechazo en frontera" previsto específicamente para Ceuta y Melilla en la Disposición Adicional $10^{\mathrm{a}}$ de la LOEx, tal como ha sido configurado en el apartado primero, para el TC, no incurre en inconstitucionalidad, sin perjuicio, de que las circunstancias concurrentes en que cada una de sus aplicaciones deban ser ponderadas convenientemente en los procesos constitucionales en que se susciten $^{72}$. Resuelve que el precepto es constitucional siempre que se interprete de conformidad con una serie de consideraciones que se hacen en el fundamento jurídico $8 \mathrm{C}$ ), concretado en los siguientes puntos: (i) aplicación a las entradas individualizadas; (ii) pleno control judicial y (iii) cumplimiento de las obligaciones internacionales. Por lo tanto, declara constitucional el establecimiento de una regulación legal singularizada de la devolución de las personas interceptadas en las vallas de Ceuta y Melilla, siempre que se cumplan las condiciones señaladas, y realiza como en otras ocasiones una interpretación del mismo.

39. Aunque la normativa establezca que el "rechazo en frontera" se realizará respetando la normativa internacional de derechos humanos y de protección internacional de la que España es parte, es

\footnotetext{
${ }^{70}$ STC 17/2013, de 31 de enero, FJ 11.

${ }^{71}$ Voto particular de la Magistrada María Luisa Balaguer Callejón a la STC 172/2020, de 19 de noviembre.

${ }^{72}$ STC 172/2020, de 19 de noviembre de 2020. Recurso de inconstitucionalidad 2896-2015, FJ 8.c).
} 
decir, que se debe realizar con las garantías que reconocen las normas a las personas extranjeras ${ }^{73}$, el TC relega esta cuestión a las disposiciones que se adopten para cumplir de un modo real y efectivo con las normas internacionales de derechos humanos que aseguren el pleno respeto a las garantías derivadas de la dignidad de la persona, que la Constitución reconoce a todas las personas sometidas a la actuación de los poderes públicos españoles ${ }^{74}$. Para ello aconseja a los cuerpos y fuerzas de seguridad que presten especial atención a las categorías de personas especialmente vulnerables, entre las que se cuentan, con distinta proyección e intensidad, las que aparenten manifiestamente ser menores de $\operatorname{edad}^{75}$, a las mujeres embarazadas o incapacitados, o, personas especialmente vulnerables. Es decir, en vez de declarar el precepto inconstitucional por vulnerar los arts. 9.3 ${ }^{\circ}$ y 106 CE flagrantemente, el TC se limita a enviar recomendaciones a las autoridades policiales y legislativas para que se pueda aplicar el precepto de manera constitucional.

40. Al margen de esta sentencia interpretativa del TC en esta cuestión tan delicada que afecta a los derechos humanos de muchas personas, no cabe duda de que cualquier devolución a Marruecos que se produzca en la valla o las inmediaciones de la misma desde Ceuta y Melilla al amparo de la Disposición Adicional $10^{\mathrm{a}}$ LOEx es una devolución que no cumple con las garantías jurídicas del art. 4 del Protocolo $\mathrm{n}^{\mathrm{o}} 4 \mathrm{y}$ art. $13 \mathrm{CEDH}$ y contraria a la normativa constitucional. El procedimiento que se debe seguir para garantizar el cumplimiento del art. 9.3, art. 24 CE y art. $106 \mathrm{CE}$ y art. $13 \mathrm{CEDH}$ y art. 47 CDFUE es el procedimiento de devolución previsto en el art. 58.3 b) de la LOEx y el art. 23 del Real Decreto 557/2011, según el cual los funcionarios de la policía fronteriza que detuvieran a un extranjero deberían escoltarlo a la comisaría de policía con miras a su identificación y posible inicio de un procedimiento de devolución. Dicho procedimiento permitiría la identificación de personas vulnerables, solicitantes de protección internacional y el derecho al recurso hasta la vía judicial pudiendo la persona interesada ser asistido gratuitamente por un abogado y un intérprete.

\section{Conclusiones}

41. Hasta el año 2015 no se pudo presentar el primer procedimiento contra las devoluciones en caliente realizadas en Ceuta y Melilla. Estas devoluciones han sido objeto de dos procedimientos ante el TEDH: el procedimiento que dio lugar a la STEDH sobre el Asunto N.D. y N.T. contra España de 3 de octubre de 2017 y posteriormente su recurso ante la Gran Sala que dio lugar a la STEDH de 13 de febrero de 2020. Dichas sentencias admiten que se ha producido una vulneración de la prohibición de las expulsiones colectivas de acuerdo con el art. 4 del Protocolo $n^{\circ} 4$ CEDH y del derecho a un recurso efectivo (art. $13 \mathrm{CEDH}$ ). No obstante, la Sentencia de la Gran Sala permite estas actividades por parte del Gobierno español en atención a la conducta de los interesados siempre que se trate de conductas realizadas por un gran número de personas y con el uso de la fuerza.

42. La conducta del interesado como justificación para las devoluciones en caliente que realiza la Gran Sala del TEDH deja vacío de contenido el art. 4. del Protocolo ${ }^{\circ} 4$ CEDH al permitir las devoluciones colectivas, imposibilitando la solicitud de asilo o protección internacional ${ }^{76}$ dentro de la

${ }^{73}$ STC 36/1991, de 14 de febrero, FJ 5: acuerdos y tratados internacionales firmados por España, lo que conecta, a través del art. 10.2 CE, con nuestro propio sistema de derechos fundamentales y libertades

${ }^{74}$ STC 53/2002, de 27 de febrero, FJ 4.

${ }^{75}$ Especialmente cuando no se encuentren acompañados por sus familiares, debiendo atender la especial salvaguardia de los derechos reconocidos en el art. 3.1 ${ }^{\circ}$ de la Convención de Naciones Unidas sobre los derechos del niño.

${ }^{76}$ En este mismo sentido se pronuncian J.L. Monereo Pérez y B.M. López Insua "Expulsiones "en caliente": proporcionalidad versus garantía de los derechos humanos al hilo de la jurisprudencia europea", La Ley: Unión Europea, no 93, junio 2021: "Claramente resulta contraria con los derechos humanos esta demoledora sentencia del Tribunal Europeo de Derechos Humanos, puesto que procede a autorizar las expulsiones colectivas de inmigrantes sin analizar las necesidades de protección y las circunstancias en las que se encuentran estas personas. No se tienen en cuenta los derechos, ni tampoco si las personas que han saltado la valla son refugiadas. Por lo que, lamentablemente, se sienta un precedente muy negativo al avalar las devoluciones en caliente, al tiempo que se niega el derecho que tienen todas las personas migrantes y refugiadas a acceder a un procedimiento 
jurisdicción española o la identificación de menores, y, especialmente el art. $13 \mathrm{CEDH}$ al impedir que los extranjeros puedan tener un mínimo de garantías jurídicas que les permita el acceso al recurso frente a la devolución. Para ello se basó en la posibilidad real de acceso por medios legales a España de los interesados que no deja de ser muy poco realista tanto en lo referido a la posibilidad de presentar la solicitud de protección internacional en los puestos fronterizos o embajadas y consulados españoles como la posibilidad de concesión de un visado de trabajo. Estas circunstancias, unidas al numeroso grupo de personas que saltaron la valla y al "uso de la fuerza", son las que, para la Gran Sala, permiten declarar que el Gobierno español no fue responsable de la conducta de los solicitantes y por tanto justificar su devolución a Marruecos sin las debidas garantías. Obvió, sin embargo, la Gran Sala, que por el hecho de encontrarse en territorio español los interesados ya eran merecedores de la protección que la legislación española otorga a los extranjeros tanto a nivel interno como a nivel internacional, de acuerdo con el art. $1^{\circ} \mathrm{CEDH}$, y que los "rechazos en frontera" no estaban regulados el 13 de agosto de 2014 (la DA $10^{\mathrm{a}}$ no entró en vigor hasta el 1 de julio de 2015).

43. En un intento de legalizar las devoluciones "en caliente" el Gobierno español incluyó la Disposición Adicional 10 a de la LOEx, a través de la LOPSC. Esta disposición adicional introduce un régimen especial en Ceuta y Melilla en el que se modifican los límites territoriales del estado español otorgando jurisdicción sobre Ceuta y Melilla a Marruecos y que además vulnera, como hemos visto, todos los principios básicos del procedimiento administrativo, la normativa de derechos humanos, así como las garantías que tienen las personas a poder solicitar asilo o protección internacional y la protección de menores. Esta regulación no era necesaria, las devoluciones o rechazos en frontera realizadas en la valla quedaban encuadradas en las devoluciones reguladas en el art. 58.3 ${ }^{\circ}$ LOEx para lo cual es necesario identificar al extranjero, dictar una resolución motivada y notificarla al interesado, con información acerca de los recursos que puedan interponerse frente a ella, el plazo para hacerlo y el órgano ante el que deban formalizarse, así como de su derecho a la asistencia letrada, que podrá ser de oficio en el caso de que el interesado carezca de recursos económicos suficientes y, en su caso, de intérprete si no comprende el idioma, el derecho a solicitar protección internacional, etc. Cualquier regulación al margen de las devoluciones del art. 58.3 LOEx debería considerarse una devolución ilegal.

44. Aun así el TC en su STC 172/2020 declaró la constitucionalidad de la Disposición Adicional $10^{\mathrm{a}}$ de la LOEx que modifica los límites geográficos con Marruecos. Además, no solo lo interpretó en el sentido expuesto por el TEDH para justificar las devoluciones colectivas en atención a la conducta del interesado, sino que también lo entiende aplicable para las devoluciones individuales. Esta interpretación choca con la doctrina del TEDH que es el intérprete máximo de las garantías del CEDH y sus protocolos, al ampliar el TC la aplicabilidad de este precepto a supuestos no autorizados como la "aplicación a las entradas individualizadas" lo que contradice, por tanto, que la DA $10^{\mathrm{a}} \mathrm{LOEx}$ se aplique con el "cumplimiento de las obligaciones internacionales".

individualizado de asilo, así como a un recurso efectivo y a la protección internacional. No cabe duda de que, con esta sentencia de 13 de febrero de 2020, el TEDH está contradiciendo la Convención de Ginebra de 1951 en la que se indica que "no debe de penalizarse a alguien que huye por haber entrado de manera irregular". 